\title{
Review Article \\ Endothelial-Leukocyte Interaction in Severe Malaria: Beyond the Brain
}

\author{
Mariana C. Souza, ${ }^{1,2}$ Tatiana A. Padua, ${ }^{1,2}$ and Maria G. Henriques ${ }^{1,2}$ \\ ${ }^{1}$ Laboratory of Applied Pharmacology, Farmanguinhos, Oswaldo Cruz Foundation, \\ Avenida Brasil 4365, Manguinhos, 21040-900 Rio de Janeiro, RJ, Brazil \\ ${ }^{2}$ National Institute for Science and Technology on Innovation on Neglected Diseases (INCT/IDN), \\ Center for Technological Development in Health (CDTS), Oswaldo Cruz Foundation (Fiocruz), Rio de Janeiro, RJ, Brazil
}

Correspondence should be addressed to Maria G. Henriques; gracahenriques@fiocruz.br

Received 19 June 2015; Revised 25 August 2015; Accepted 1 September 2015

Academic Editor: Pilar Alcaide

Copyright (C) 2015 Mariana C. Souza et al. This is an open access article distributed under the Creative Commons Attribution License, which permits unrestricted use, distribution, and reproduction in any medium, provided the original work is properly cited.

\begin{abstract}
Malaria is the most important parasitic disease worldwide, accounting for 1 million deaths each year. Severe malaria is a systemic illness characterized by dysfunction of brain tissue and of one or more peripheral organs as lungs and kidney. The most severe and most studied form of malaria is associated with cerebral complications due to capillary congestion and the adhesion of infected erythrocytes, platelets, and leukocytes to brain vasculature. Thus, leukocyte rolling and adhesion in the brain vascular bed during severe malaria is singular and distinct from other models of inflammation. The leukocyte/endothelium interaction and neutrophil accumulation are also observed in the lungs. However, lung interactions differ from brain interactions, likely due to differences in the blood-brain barrier and blood-air barrier tight junction composition of the brain and lung endothelium. Here, we review the importance of endothelial dysfunction and the mechanism of leukocyte/endothelium interaction during severe malaria. Furthermore, we hypothesize a possible use of adjunctive therapies to antimalarial drugs that target the interaction between the leukocytes and the endothelium.
\end{abstract}

\section{Introduction}

Malaria is the most important parasitic disease worldwide. It is present in more than 100 countries, putting 1.2 billion people at risk and accounting for more than 800 thousand deaths each year $[1,2]$. Cerebral malaria $(\mathrm{CM})$ is the most severe form of malaria and is usually found in children under five years old [3]. Clinically, CM is defined by the identification of $P$. falciparum in peripheral blood, convulsions, and coma, after ruling out any other cause of coma such as meningitis [4,5]. Pathological findings such as capillary congestion, production of proinflammatory cytokines, and adhesion of infected red blood cells (iRBC) to brain vasculature are responsible for cerebral complications associated with CM [6]. In some patients, a systemic illness called severe malaria (SM) is observed which is characterized by one or more peripheral organ dysfunctions as acute lung injury (ALI)/acute respiratory distress syndrome (ARDS) [7] and acute kidney injury $[8,9]$ and can be combined with cerebral malaria signals [10]. Some authors suggest that SM is due to pathological events such as parasitized erythrocytes, leukocyte adhesion to the organ microvasculature, systemic production of cytokines, and cytotoxic lymphocyte activation $[11,12]$. Despite systemic activation, the leukocyte/endothelial cell interaction differs depending on the studied organ. Here, we discuss endothelial dysfunction during severe malaria and the mechanisms by which leukocytes adhere to the endothelium in distinct organs during this pathology.

\section{Leukocyte-Endothelium Interaction during Cerebral Malaria}

A main characteristic of brain physiology is the immune privilege conferred by the $\mathrm{BBB}$ to brain tissue [13]. However, the $\mathrm{BBB}$ composition, especially in the postcapillary venule, allows leukocyte diapedesis during nonmalarial brain injury $[14,15]$. 
During human cerebral malaria, the importance of infected red blood cells adhesion to brain microvasculature is well established [5]. Necropsy of fatal cases of severe malaria shows the adhesion of $\mathrm{iRBC}$ in the venules and capillaries, causing congestion $[6,16,17]$. The mechanism of iRBC adhesion to brain microvasculature is well described and depends on expression of membrane proteins such as $P$. falciparum erythrocyte membrane proteins (PfEMP1) [18]. However, the leukocyte-endothelium interaction during human cerebral malaria is not completely clarified $[12,16$, $19,20]$. Indeed, it is well established that both endothelium [21] and leukocyte $[22,23]$ are activated in patients diagnosed with $\mathrm{CM}$; however, how they orchestrate the brain injury to develop CM is still not well understood.

Endothelium activation markers have been used in clinical studies to predict malaria severity [24, 25]. During CM, the endothelium can be activated by different mechanisms as the binding of soluble proteins present in host serum [24], direct contact with iRBC [6], and activation induced by parasite-derived molecules as hemozoin [26] and GPI [27]. Necropsy performed in fatal cases of CM showed increased expression of adhesion molecules on brain microvasculature [28] supporting the idea that the endothelium is able to promote leukocyte adhesion. Some studies show the presence of leukocyte in brain vasculature lumen [16] or in perivascular space [29], although there are no lines of evidence of the importance of leukocyte adhesion to brain vasculature in development of human CM. However, it cannot be ruled out considering the lack of knowledge in this issue $[16,20]$.

The interaction between leukocytes and endothelial cells during human CM could not depend on cell-cell contact. Instead, leukocytes and lymphocytes produce inflammatory mediators as TNF- $\alpha$ which activate endothelial cells $[28,30]$. Endothelial activation induced by TNF- $\alpha$ accounts for many factors involved in development of CM [31] as increased iRBC adhesion [30], expression of leukocyte chemotactic factors [32] and, costimulated by iRBC, increases ICAM-1 expression that improve iRBC adhesion [30].

On the other hand, the adhesion of leukocytes to brain vasculature is often observed during experimental cerebral malaria $[33,34]$. A recent report revealed that the majority of leucocytes accumulated in the brain during experimental severe malaria are monocytes. These cells are responsible for the recruitment of $\mathrm{CD}^{+}$and $\mathrm{CD}^{+} \mathrm{T}$ cells to the CNS vasculature [35]. However, in the absence of monocytes, $\mathrm{T}$ cells are still recruited to the brain to initiate experimental cerebral malaria [35]. Observation of the microvessels within the brains of live animals demonstrated the marginalization of leukocytes and platelets aggregates in postcapillary brain venules but not in capillaries of $P$. berghei-infected mice, showing that leukocytes do not accumulate in brains tissue but induce endothelium dysfunction, leading to vascular leakage, neurological signs, and coma [35, 36]. The role of adhesion molecules, especially ICAM-1, in the leukocyte/endothelium interaction to promote cerebral dysfunction during experimental severe malaria is controversial. The impairment of the ICAM-1/ $\beta 2$-integrin complex abolishes the development of cerebral dysfunction associated with $P$. berghei infection [36-38]. However, Ramos and colleagues deleted ICAM-1 in different cells and showed that only ICAM-1 expressed in leukocytes accounts for experimental severe malaria [39]. The authors speculated that because endothelial cells do not express ICAM-1 counter receptor, leukocytes, platelets, and iRBC aggregates occlude brain microvessels and promote cerebral malaria [39].

A new approach of leukocyte and endothelium interaction in brain during $\mathrm{CM}$ has been proposed through interaction between $\mathrm{MHC}$ class I molecules and $\mathrm{CD}^{+}{ }^{+} \mathrm{T}$ lymphocytes. Recent studies regarding experimental CM show that the membranes of endothelial cells and iRBC fuse by trogocytosis, resulting in the expression of Plasmodium antigens [40]. Endothelial cells preferentially phagocytize merozoites and, via proteasome digestion, present plasmodial antigens by $\mathrm{MHC}$ class I molecules to $\mathrm{CD}^{+} \mathrm{T}$ lymphocytes, thus contributing to the adaptive immune response to $P$. berghei infection [41]. It is noteworthy that the same results were observed within $P$. falciparum phagocytosis by human endothelial cells [41]. However, P. falciparum phagocytosis by endothelial cells in vivo and its clinical relevance remain to be elucidated.

Overall, microvascular congestion observed in both human and experimental CM leads to severe cerebral endothelial damage, resulting in the breakdown of the BBB mainly at the level of postcapillary venules $[16,29,31,42]$. The postcapillary venule $\mathrm{BBB}$ (Figure 1) is functionally distinct from other $\mathrm{BBB}$ areas and is in direct contact with the perivascular space [42]. In light of the new findings concerning brain anatomy in which the authors described the presence of lymphatic vessels in direct contact with the perivascular space in the central nervous system, in the next few years, the dynamics of the interaction between leukocytes and the endothelium during cerebral malaria will likely be unveiled [43].

\section{Leukocyte-Endothelium Interaction in the Lung during Malaria}

The brain is not the only organ affected during severe malaria. Twenty percent of patients diagnosed with severe malaria develop acute lung injury (ALI) and acute respiratory distress syndrome (ARDS) [7, 9]. ALI/ARDS is a syndrome derived from pathological conditions such as sepsis and traumatic brain injury. ALI/ARDS diagnosis includes the identification of respiratory failure, diffuse alveolar damage, and inflammatory infiltration in lung tissue [44]. Necropsy in fatal cases of severe malaria revealed that patients present classical symptoms of ALI, including pulmonary edema, pulmonary capillary congestion, thickened alveolar septa, marked inflammatory response in lung tissue, and macrophages in the lumen of the pulmonary capillaries [11]. Murine experimental models of severe malaria also present pulmonary pathology such as edema, cell infiltration, tissue damage, and lung mechanical impairment [45-48]. Furthermore, the lung appears to be a large reservoir of metabolically active parasites, as described in an elegant study by Lovegrove et al. who evaluated the transcriptional responses to Plasmodium in different organs [49].

The lung vasculature in malaria infection is essential to initiate the Plasmodium cycle within the host. When merozoites leave the liver, they are located inside host-derived 


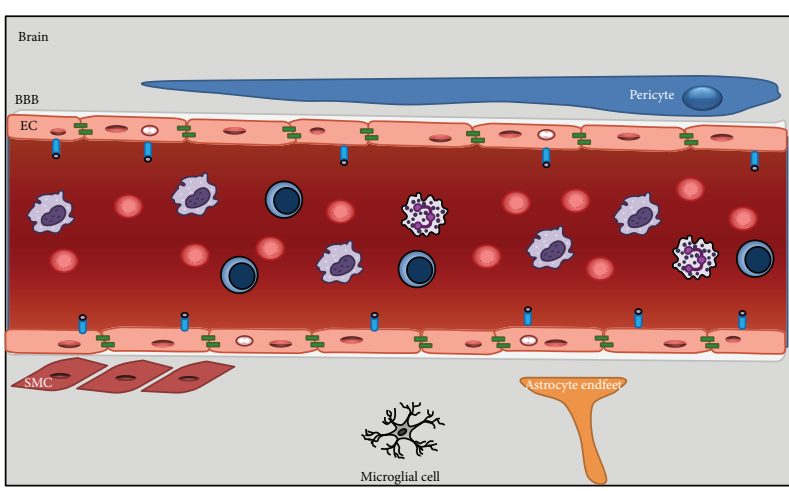

(a)

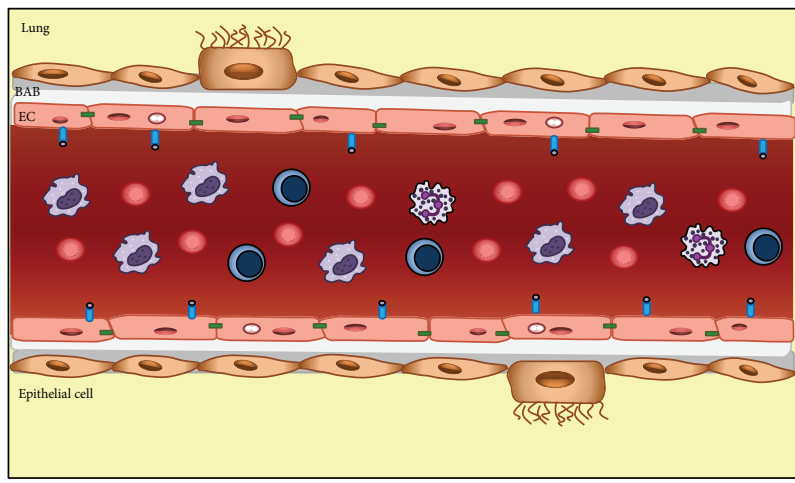

(b)

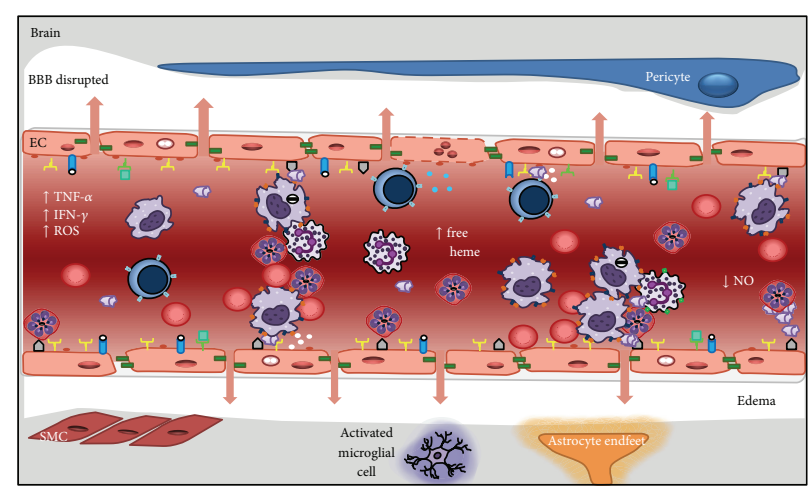

(c)

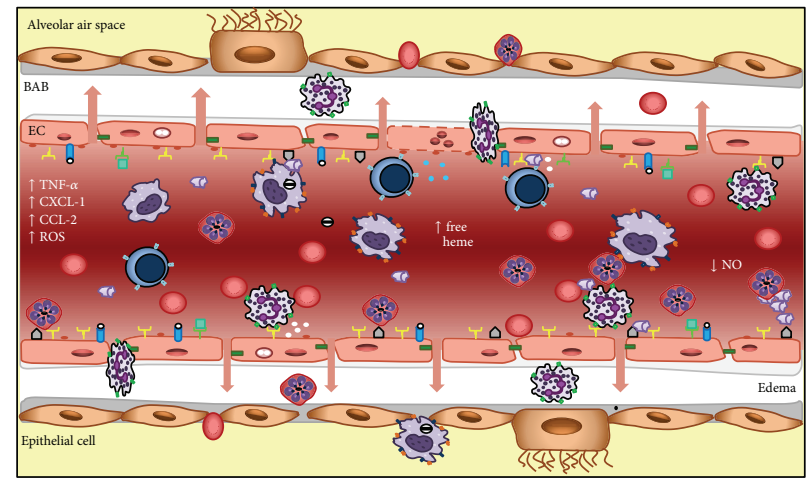

(d)

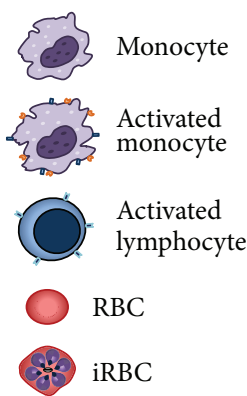

9 Ang-2-tie2 axis

f Ang-1-tie2 axis

Cellular adhesion molecules

Activated protein $\mathrm{C} / \mathrm{EC}$ protein C receptor

$\triangle$ Selectins

$\ominus$ Hemozoin crystal

FIGURE 1: Blood barrier differences between brain and lung during malaria. (a) Cerebral microvasculature and (b) lung microvasculature without leucocytes attached in postcapillary venules and EC expressing Ang-1, under physiological conditions. (c) During severe malaria, we observe production of proinflammatory cytokines, increase of cellular adhesion molecules expression, release of Ang-2, decrease of NO, and adhesion of $\mathrm{iRBC}$ and leukocytes (mainly mononuclear cells) to brain vasculature leading to capillary congestion, BBB dysfunction, and edema. Such events activate the subjacent tissue (microglial cells and astrocytes). (d) Acute lung injury (ALI) and acute respiratory distress syndrome (ARDS) associated with malaria. The augment of inflammatory cytokines and chemokines, release of Ang-2, and decrease of NO are responsible for activation of EC that increases the expression of cellular adhesion molecules allowing the margination and infiltration of iRBC, leucocytes, and platelets into blood vessels, interstitial tissue, and consequently alveolar air space. BBB: blood-brain barrier; BAB: blood-air barrier; EC: endothelial cell; ROS: reactive oxygen species; SMC: smooth muscle cell.

buds named merosomes, whose membranes are disrupted within the pulmonary capillary beds to allow merozoites to reach the erythrocytes $[50,51]$. The close contact between infected erythrocytes and pulmonary endothelial cells triggers a remarkable inflammatory response $24 \mathrm{~h}$ after infection, characterized by intense inflammatory cell infiltration as well as the production of proinflammatory cytokines and chemokines in lung tissue that persists for at least five days after infection [45-47]. The quantity of parasites in lung tissue defines the extent of chemokine production in lung tissue [52]. Chemokines such as CCL2, CXCL1, and CCL5 are produced in lungs during experimental malaria and are correlated with macrophage and neutrophil accumulation in pulmonary tissue $[45,53,54]$. Intravital studies in lungs of Plasmodium-infected mice reveled edema formation and the migration of monocytes and neutrophils to lung tissue [37]. However, due to the technical limitations in studying leukocyte mobility within the lung [55], until now, there have 
been no available data on the dynamics of leukocytes and lung endothelium during malaria-triggered ALI [37]. Indeed, lung endothelial cells are activated during malaria infection and express adhesion molecules. P-selectin, in addition to Land E-selectin, is part of a family of calcium-dependent (Ctype) lectins whose activation induces the expression of $\beta 2$ integrins and consequent leukocyte arrest in the vasculature $[56,57]$. P-selectin is expressed in both lung and brain endothelium during experimental malaria. This molecule mediates leukocyte rolling in brain microvessels of $P$. bergheiinfected mice; however, it is not essential for development of experimental cerebral malaria signals [58]. On the other hand, the monocyte/macrophage accumulation in lungs of $P$. berghei-infected mice depends on the expression of ICAM-1 $[52,59]$, while ICAM-1 expression in the brains of infected mice does not account for leukocyte adhesion [60]. It is interesting to note that while inflammatory cell infiltration in cerebral tissue was not observed in the brain, neutrophil and macrophage infiltration is frequently observed in pulmonary interstitial lung tissue during malaria [45]. Indeed, differences in the blood-brain barrier and blood-air barrier tight junction constitution of the brain and lung are responsible for this phenomenon (Figure 1).

The morphological and biochemical differences between lung and brain endothelial cells account for the distinct inflammatory responses in both organs. Despite both endothelial cell types containing nonfenestrated endothelium, brain endothelial cells present fewer caveolae and are richer in tight junctions than lung endothelium [61, 62]. The lung endothelial bed is rich in adherens junctions and P-selectins and allows leukocyte transmigration by paracellular and transcellular pathways [61, 62]. Endothelial cells from lung tissue can be activated by VEGF [4], TNF$\alpha$ [63], LPS [64], and P. falciparum infected erythrocytes, resulting in the reorganization of their junctional proteins [63]. In addition to inflammatory mediators and pathogenassociated molecular pattern (PAMP), the leukocyte contact also contributes to endothelial cell reorganization, triggering a dephosphorylation cascade followed by the endocytosis of VE-cadherins, which support leukocyte transmigration through lung endothelial cells [65]. Of note, in most organs, leukocyte transmigration happens almost exclusively in postcapillary venules. However, in the lung leukocyte transmigration occurs in capillaries of the blood-air barrier which are surrounded by epithelium forming alveoli [61].

In addition to the direct interaction between leukocytes and the endothelium described earlier, leukocytes can bind platelets and then adhere to the endothelium. Piguet and colleagues showed that platelet and mononuclear cell trapping occurs in the lungs of $P$. berghei-infected mice [66]. In addition, the authors observed that the impairment of platelet activation decreased leukocyte adhesion to the lung vasculature of $P$. berghei-infected mice [66]. The stimulation of the receptor $\mathrm{P}_{2} \mathrm{Y}_{1}$ but not $\mathrm{P}_{2} \mathrm{Y}_{12}$ on platelets induces the downstream activation of the RhoA pathway, resulting in platelet/leukocyte aggregation and migration to the lung [67]. In addition, platelets also contribute to the leukocyte/endothelium interaction by releasing microparticles. Neutrophils stimulated with platelet-derived microparticles increased the expression of $\alpha \mathrm{M}$ integrin and adhered to pulmonary endothelial cells via ICAM-1 [68].

The study of leukocyte/endothelium interactions within the lung during malaria is limited but extremely important. Mice depleted of neutrophils showed reduced malaria associated ALI and delayed mortality [38], suggesting that further studies are necessary to show the mechanism of the leukocyte/endothelial interaction in the lung during severe malaria.

\section{Leukocyte/Endothelium Interaction during Malaria as a Target for Treatment}

In accordance with the findings presented above both in human and animals, the leukocyte/endothelium interaction plays a role in the development of pathogenesis of severe malaria particularly in malaria-induced ALI [9, 12, 45, 47]. In fact, lung dysfunction triggered in both human and experimental malaria shares similarities with lung mechanics impairment, pulmonary edema, production of inflammatory cytokines, and inflammatory cells infiltration in lung tissue $[9,45]$. Furthermore, the inflammatory response persists even after the host is cured of infection $[10,69,70]$ (unpublished data), which suggests that modulation of inflammatory response in addition to antimalarial therapy would be helpful to patient outcome [71]. The leukocyte-endothelium interaction is not the most important factor regarding development of human cerebral malaria pathogenesis; however, it should not be neglected as actor in severe malaria-induced organ dysfunction.

Recently, Frosch and John suggested that an adjunctive therapy that impaired the inflammatory response induced during malaria should be combined with antimalarial drugs [72]. Several approaches have already aimed at the modulation of the malaria-induced inflammatory response. Figure 2 illustrates several potential targets described in the literature. Patients diagnosed with severe malaria have been treated with modulators of TNF- $\alpha$ production [73], CD36 expression $[74,75]$, NO precursors $[70,76]$, or adhesion of iRBC to vasculature [77] and presented decreased inflammation scores when compared to a placebo treated group. Despite evidence suggesting that the modulation of leukocyte and endothelial activation supports the outcome of severe malaria, it is not clear whether an adjunctive therapy targeting the leukocyte/endothelium interaction would predict patient outcome. It is worth noting that the most important class of antimalarial drug to treat severe malaria is artemisinin and its derivatives [78], which also have immunomodulatory activities in pathologies such as microbial infections, tumor growth, and inflammatory diseases [79-82]. Our group demonstrated that, in addition to its antimalarial properties, artesunate exerted a protective effect against severe malaria via its immunomodulatory properties by inhibiting endothelial cell activation, NF- $\kappa \mathrm{B}$ nuclear translocation, and the subsequent expression of ICAM-1 [83].

Srinivas and colleagues studied the effect of treatment with activated protein $C$ on a patient with severe malaria coinfected with leptospirosis and observed a rapid outcome 

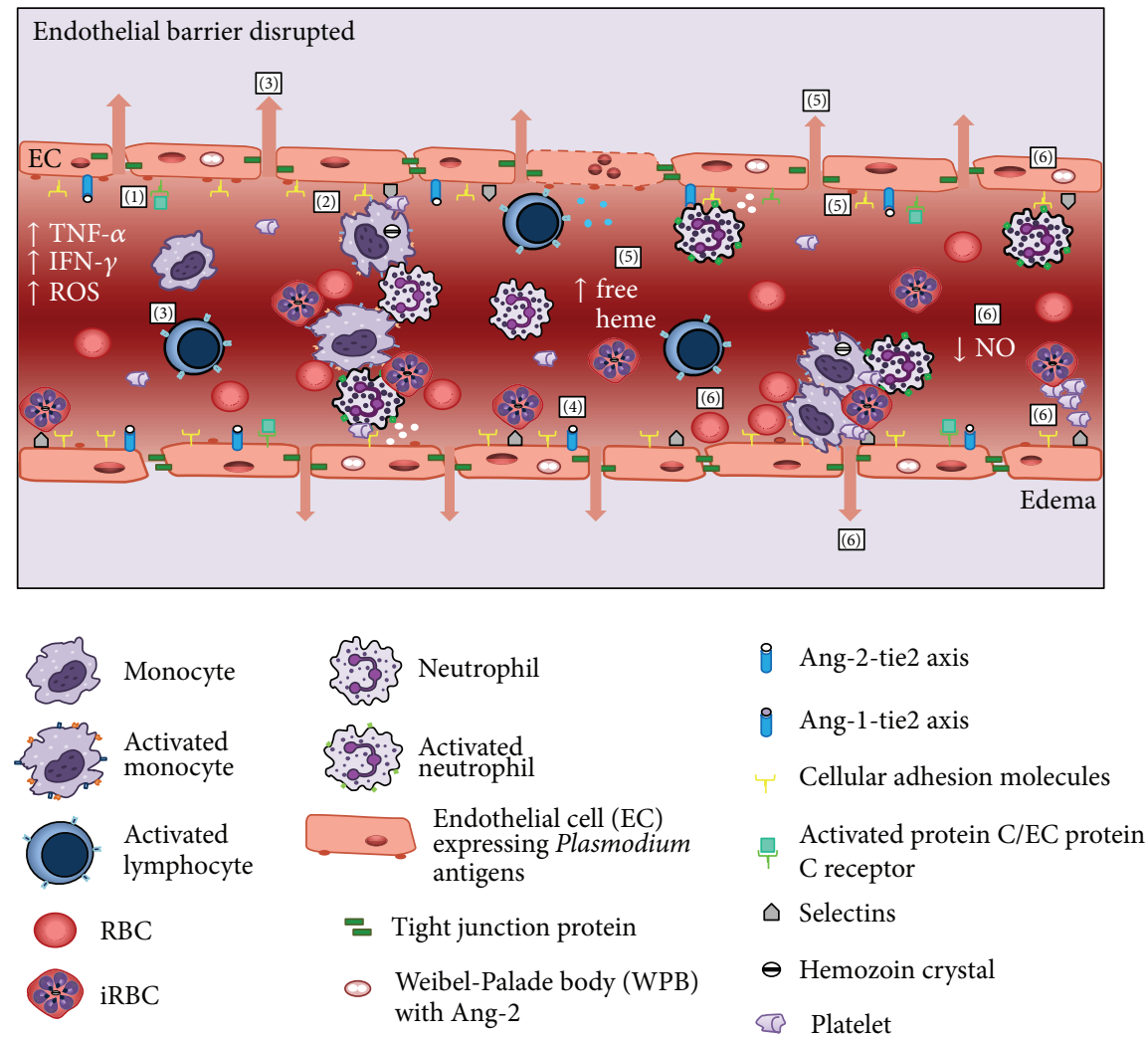

FIGURE 2: Targets of adjuvant therapies during malaria. Scheme showing several approaches that have been investigated aiming at modulation of malaria-induced inflammatory response. EC: endothelial cell; ROS: reactive oxygen species; SMC: smooth muscle cell. (1) Activated protein $C$ binds to protein $C$ receptor in activated EC cells decreasing the expression of adhesion molecules. (2) Statins decrease the production of chemokine and diminished the adhesion of leukocytes to brain microvasculature. (3) Sphingosine-1-phosphate (S1P) decreases the numbers of lymphocytes in brain vasculature and stabilizes the tight junction protein ZO-1 in brains. (4) Neuregulin-1 and bone marrow mesenchymal stromal cells induce Ang-1, which promotes stabilization of EC tight junctions, EC desensitization to TNF- $\alpha$, and downregulation of ICAM1 and VCAM-1. (5) Lipoxin $A_{4}$ decreases production of proinflammatory cytokines, impairs EC activation, and inhibits the expression of cellular adhesion molecules involved in leukocyte adhesion by stimulating the activity of HO-1, which catabolizes free heme. (6) L-Arginine or inhaled NO (iNO) reduces pulmonary edema and, in addition, decreases cytoadherence of iRBC, hemorrhagic foci, and leukocyte and platelets adherence to brain vasculature by inhibiting of WPB exocytosis that impairs the release of Ang- 2 and inhibiting TNF- $\alpha$ production and procoagulant activity of endothelial cells.

[84]. The binding of activated protein $\mathrm{C}$ to endothelial cell protein $\mathrm{C}$ receptor in activated endothelial cells avoided $\mathrm{NF}-\kappa \mathrm{B}$ p 65 phosphorylation and induced AKT signaling, which decreased the expression of adhesion molecules on the endothelial cell surface $[18,85]$. Thus, activated protein $\mathrm{C}$ in malaria would increase endothelial barrier integrity, induce antiapoptotic pathways, and decrease adhesion molecule expression [86]. Other modulators of endothelial functions have been used to evaluate malaria outcome in humans and experimental models. Studies in which $P$. berghei-infected mice were treated with statins, a class of drugs that inhibit the rate-limiting step in cholesterol synthesis and that show pleiotropic effects, demonstrated that statins decreased the production of chemokines [87] and decreased the adhesion of leukocytes to the brain microvasculature [88] probably by inhibiting the binding site of LFA-1 on leukocytes [89]. Accordingly, in vitro treatment of human endothelial cells with statins followed by stimulation with $P$. falciparuminfected erythrocytes decreased the expression of adhesion molecules, suggesting that statins could exert an antiadhesive role in the treatment of severe malaria [90]. Statins have not been tested in clinical trials for malaria adjunctive treatment. However, statins diminished the risk of sepsisrelated mortality in patients, probably by decreasing the inflammatory response triggered during sepsis [91].

The endothelial barrier stabilizer sphingosine-1-phosphate (S1P) also rescued mice from severe malaria by decreasing the numbers of $\mathrm{CD}^{+}, \mathrm{CD}^{+}$, and $\mathrm{CD} 45^{+}$cells in the brain vasculature of $P$. berghei-infected mice, likely decreasing ICAM-1 expression and stabilizing the tight junction protein ZO-1 in brains $[36,92]$. Transfection of bone marrow mesenchymal stromal cells and administration of S1P and other endothelial barrier stabilizers such as neuregulin-1 induce the endogenous Ang-1 anti-inflammatory pathway, which promotes decreased vascular permeability by stabilizing endothelial cell tight junctions, endothelial cell desensitization to TNF- $\alpha$, and downregulating ICAM-1 and VCAM-1. These Ang-1 actions result in decreased leukocyte/endothelial interaction and, consequently, host outcome [4, 93-97]. 
Another family of lipids has been studied for its antiinflammatory activity during severe malaria. Lipoxins (LX) are products of arachidonic acid metabolism and are produced through sequential lipoxygenase activity following cell-cell interactions in the inflammatory milieu (reviewed by [98]). The interaction of $\mathrm{LXA}_{4}$ and its receptor ALX has anti-inflammatory and proresolving activity in inflammatory models such as allergic airway inflammation [99] and autoimmune diseases [100] by reducing leukocyte adhesion to endothelial cells [101]. The administration of $\mathrm{LXA}_{4}$ improved survival in $P$. berghei-infected mice by decreasing the production of proinflammatory cytokines but not the accumulation of $\mathrm{CD}^{+} / \mathrm{IFN}-\gamma^{+}$cells in brain tissue [102]. In addition to $\mathrm{LXA}_{4}$ impairment of leukocyte activation, the mechanism of action of $\mathrm{LXA}_{4}$ on endothelium during severe malaria was recently disclosed by intravital studies of the microvasculature of $P$. berghei-infected mice. The authors showed that treatment with $\mathrm{LXA}_{4}$ did not modulate leukocyte adhesion to the brain vasculature or decrease the expression of $\beta 2$-integrin in leukocytes (unpublished data). On the other hand, treatment with $\mathrm{LXA}_{4}$ impaired endothelial activation during severe malaria and restored the blood flow in brains of $P$. berghei-infected mice [33]. The authors also showed that $\mathrm{LXA}_{4}$ exerted its effects by stimulating the activity of heme oxygenase 1 (HO-1), an isoenzyme that catabolizes free heme released under pathological conditions, especially in pathologies such as malaria which are associated with intravascular hemolysis [33]. HO-1 upregulation helps maintain BBB integrity under pathological conditions [103]. During the inflammatory response, HO-1 inhibits the expression of several adhesion molecules involved in leukocyte adhesion to endothelial cells [104, 105]. During experimental severe malaria, $\mathrm{HO}-1$ is differentially regulated in certain tissues at different stages of Plasmodium life cycle $[106,107]$. Furthermore, HO-1 production in brain tissue is associated with mouse survival, decreased cerebral edema, and decreased leukocyte adhesion to brain vasculature [106].

In hemolytic disorders such as malaria, low bioavailability of NO is observed, as free hemoglobin is a potent scavenger of this gaseous molecule [108]. Therefore, the administration of L-arginine or inhaled NO (iNO) has also been tested as adjunctive therapy in the treatment of severe malaria [4, 76]. Yeo and collaborators showed that impaired endothelial NO production occurred in severe malaria in both children and adults, supporting the idea that further trials of drugs that led to increased endothelial NO bioavailability could attenuate severe malaria symptoms [109]. Studies in which severe malaria patients were treated with inhaled nitric oxide demonstrated that NO reduced pulmonary edema in patients with malaria-derived ALI and decreased pulmonary capillary pressure through selective vasodilatory effects on postcapillary venules [110]. Thus, in severe malaria, nitric oxide is hypothesized to promote vascular quiescence, decrease cytoadherence of parasitized erythrocytes to the microvascular endothelium as a critical mediator of VEGF and Ang1 , and dampen inflammatory responses and thrombosis [4]. Nitric oxide (NO) is a short-lived free radical formed from $\mathrm{L}$-arginine conversion that is involved in many important biological functions including neurotransmission, immune system, cytokine modulation platelet inhibition, vascular homeostasis, and regulation of hematopoiesis [111]. Its production occurs through three different NO synthase (NOS) enzyme isoforms: neuronal NOS (nNOS or NOS1), inducible NOS (iNOS or NOS2), and endothelial NOS (eNOS or NOS3) [111]. The constitutive isoforms (neuronal and endothelial) are calcium/calmodulin dependent and permanently active, generating low concentrations of NO. The inducible isoform (iNOS) is only expressed when its transcription is activated by a variety of cytokines, growth factors, and inflammatory stimuli on target cells, leading to the release of high levels of NO [112]. In experimental severe malaria, treatment with exogenous NO (NO donor dipropylenetriamine NONOate, DPTA-NO) showed improved pial blood flow, diminished hemorrhagic foci, and reduced leukocyte and platelet adherence to the brain vasculature $[113,114]$. The authors hypothesize that $\mathrm{NO}$ attenuates malaria symptoms by (a) inhibition of Weibel-Palade body exocytosis and the consequent release of Ang-2 and increase in Ang-1 expression; (b) decreasing the endothelial expression of ICAM-1 and VCAM-1; (c) inhibiting TNF- $\alpha$ production; (d) inhibiting the procoagulant activity of endothelial cells; and (e) decreasing intravascular platelet aggregation $[108,110,111]$.

Indeed, pathophysiological phenomena experienced during experimental severe malaria are not fully translated to human severe malaria [115-118]. Therefore, further studies should be performed before initiating clinical studies of immunomodulatory drugs as adjunctive therapy for severe malaria.

\section{Disclosure}

Tatiana Pádua is a student of the Graduate Program in Cellular and Molecular Biology from Oswaldo Cruz Institute, Fiocruz, Rio de Janeiro, Brazil.

\section{Conflict of Interests}

The authors declare that there is no conflict of interests regarding the publication of this paper.

\section{Acknowledgments}

This work was supported by Fundação Carlos Chagas Filho de Amparo à Pesquisa do Estado do Rio de Janeiro (FAPERJ) and Conselho Nacional de Desenvolvimento Científico e Tecnológico (CNPq).

\section{References}

[1] WHO, "WHO guidelines approved by the guidelines review committee," in Guidelines for the Treatment of Malaria, World Health Organization, Geneva, Switzerland, 2015.

[2] C. Murray and R. Chambers, "Keeping score: fostering accountability for children's lives," The Lancet, vol. 386, no. 9988, pp. 3-5, 2015.

[3] K. B. Seydel, S. D. Kampondeni, C. Valim et al., "Brain swelling and death in children with cerebral malaria," The New England Journal of Medicine, vol. 372, no. 12, pp. 1126-1137, 2015. 
[4] H. Kim, S. Higgins, W. C. Liles, and K. C. Kain, "Endothelial activation and dysregulation in malaria: a potential target for novel therapeutics," Current Opinion in Hematology, vol. 18, no. 3, pp. 177-185, 2011.

[5] S. C. Wassmer, T. E. Taylor, P. K. Rathod et al., "Investigating the pathogenesis of severe malaria: a multidisciplinary and cross-geographical approach," The American Journal of Tropical Medicine and Hygiene, vol. 93, no. 3, supplement, pp. 42-56, 2015.

[6] T. E. Taylor and M. E. Molyneux, "The pathogenesis of pediatric cerebral malaria: eye exams, autopsies, and neuroimaging," Annals of the New York Academy of Sciences, vol. 1342, no. 1, pp. 44-52, 2015.

[7] A. Mohan, S. K. Sharma, and S. Bollineni, "Acute lung injury and acute respiratory distress syndrome in malaria," Journal of Vector Borne Diseases, vol. 45, no. 3, pp. 179-193, 2008.

[8] J. Abdul Manan, H. Ali, and M. Lal, "Acute renal failure associated with malaria," Journal of Ayub Medical College, Abbottabad, vol. 18, no. 4, pp. 47-52, 2006.

[9] W. R. J. Taylor, J. Hanson, G. D. H. Turner, N. J. White, and A. M. Dondorp, "Respiratory manifestations of malaria," Chest, vol. 142, no. 2, pp. 492-505, 2012.

[10] G. P. Maguire, T. Handojo, M. C. F. Pain et al., "Lung injury in uncomplicated and severe falciparum malaria: a longitudinal study in Papua, Indonesia," Journal of Infectious Diseases, vol. 192, no. 11, pp. 1966-1974, 2005.

[11] D. Milner Jr., R. Factor, R. Whitten et al., "Pulmonary pathology in pediatric cerebral malaria," Human Pathology, vol. 44, no. 12, pp. 2719-2726, 2013.

[12] D. A. Milner Jr., R. O. Whitten, S. Kamiza et al., "The systemic pathology of cerebral malaria in African children," Frontiers in Cellular and Infection Microbiology, vol. 4, article 104, 2014.

[13] M. G. Harris, P. Hulseberg, C. Ling et al., "Immune privilege of the CNS is not the consequence of limited antigen sampling," Scientific Reports, vol. 4, article 4422, 2014.

[14] A. Alfieri, S. Srivastava, R. C. M. Siow et al., "Sulforaphane preconditioning of the Nrf2/HO-1 defense pathway protects the cerebral vasculature against blood-brain barrier disruption and neurological deficits in stroke," Free Radical Biology and Medicine, vol. 65, pp. 1012-1022, 2013.

[15] N. M. Silva, R. M. Manzan, W. P. Carneiro et al., “Toxoplasma gondii: the severity of toxoplasmic encephalitis in C57BL/6 mice is associated with increased ALCAM and VCAM-1 expression in the central nervous system and higher blood-brain barrier permeability," Experimental Parasitology, vol. 126, no. 2, pp. 167$177,2010$.

[16] K. Dorovini-Zis, K. Schmidt, H. Huynh et al., "The neuropathology of fatal cerebral malaria in Malawian children," The American Journal of Pathology, vol. 178, no. 5, pp. 2146-2158, 2011.

[17] G. G. MacPherson, M. J. Warrell, N. J. White, and S. Looareesuwan, "Human cerebral malaria. A quantitative ultrastructural analysis of parasitized erythrocyte sequestration," The American Journal of Pathology, vol. 119, no. 3, pp. 385-401, 1985.

[18] L. Turner, T. Lavstsen, S. S. Berger et al., "Severe malaria is associated with parasite binding to endothelial protein $\mathrm{C}$ receptor," Nature, vol. 498, no. 7455, pp. 502-505, 2013.

[19] J. K. Patnaik, B. S. Das, S. K. Mishra, S. Mohanty, S. K. Satpathy, and D. Mohanty, "Vascular clogging, mononuclear cell margination, and enhanced vascular permeability in the pathogenesis of human cerebral malaria," American Journal of Tropical Medicine and Hygiene, vol. 51, no. 5, pp. 642-647, 1994.
[20] C. Punsawad, Y. Maneerat, U. Chaisri, K. Nantavisai, and P. Viriyavejakul, "Nuclear factor kappa B modulates apoptosis in the brain endothelial cells and intravascular leukocytes of fatal cerebral malaria," Malaria Journal, vol. 12, article 260, 12 pages, 2013.

[21] F. García, M. Cebrián, M. Dgedge et al., "Endothelial cell activation in muscle biopsy samples is related to clinical severity in human cerebral malaria," The Journal of Infectious Diseases, vol. 179, no. 2, pp. 475-483, 1999.

[22] M. Krupka, K. Seydel, C. M. Feintuch et al., "Mild Plasmodium falciparum malaria following an episode of severe malaria is associated with induction of the interferon pathway in Malawian children," Infection and Immunity, vol. 80, no. 3, pp. 1150-1155, 2012.

[23] S. Worku, M. Troye-Blomberg, B. Christensson, A. Björkman, and T. Fehniger, "Activation of T cells in the blood of patients with acute malaria: proliferative activity as indicated by Ki-67 expression," Scandinavian Journal of Immunology, vol. 53, no. 3, pp. 296-301, 2001.

[24] A. L. Conroy, S. J. Glover, M. Hawkes et al., "Angiopoietin-2 levels are associated with retinopathy and predict mortality in Malawian children with cerebral malaria: a retrospective casecontrol study"," Critical Care Medicine, vol. 40, no. 3, pp. 952959, 2012.

[25] V. Jain, N. W. Lucchi, N. O. Wilson et al., "Plasma levels of angiopoietin-1 and -2 predict cerebral malaria outcome in Central India," Malaria Journal, vol. 10, article 383, 2011.

[26] M. Prato, S. D’Alessandro, P. E. Van den Steen et al., "Natural haemozoin modulates matrix metalloproteinases and induces morphological changes in human microvascular endothelium," Cellular Microbiology, vol. 13, no. 8, pp. 1275-1285, 2011.

[27] S. D. Tachado, P. Gerold, M. J. McConville et al., "Glycosylphosphatidylinositol toxin of Plasmodium induces nitric oxide synthase expression in macrophages and vascular endothelial cells by a protein tyrosine kinase-dependent and protein kinase Cdependent signaling pathway," Journal of Immunology, vol. 156, no. 5, pp. 1897-1907, 1996.

[28] H. Armah, E. K. Wiredu, A. K. Dodoo, A. A. Adjei, Y. Tettey, and R. Gyasi, "Cytokines and adhesion molecules expression in the brain in human cerebral malaria," International Journal of Environmental Research and Public Health, vol. 2, no. 1, pp. 123131, 2005.

[29] H. Brown, T. T. Hien, N. Day et al., "Evidence of blood-brain barrier dysfunction in human cerebral malaria," Neuropathology and Applied Neurobiology, vol. 25, no. 4, pp. 331-340, 1999.

[30] Y. Wu, T. Szestak, M. Stins, and A. G. Craig, "Amplification of $P$. falciparum cytoadherence through induction of a pro-adhesive state in host endothelium," PLoS ONE, vol. 6, no. 10, Article ID e24784, 2011.

[31] J. Storm and A. G. Craig, "Pathogenesis of cerebral malariaâinflammation and cytoadherence," Frontiers in Cellular and Infection Microbiology, vol. 4, article 100, 2014.

[32] S. J. Chakravorty, C. Carret, G. B. Nash, A. Ivens, T. Szestak, and A. G. Craig, "Altered phenotype and gene transcription in endothelial cells, induced by Plasmodium falciparum-infected red blood cells: pathogenic or protective?" International Journal for Parasitology, vol. 37, no. 8-9, pp. 975-987, 2007.

[33] M. C. Souza, T. A. Pádua, N. D. Torres et al., "Lipoxin $\mathrm{A}_{4}$ attenuates endothelial dysfunction during experimental cerebral malaria," International Immunopharmacology, vol. 24, no. 2, pp. 400-407, 2015. 
[34] A. Nacer, A. Movila, F. Sohet et al., "Experimental cerebral malaria pathogenesis-hemodynamics at the blood brain barrier," PLoS Pathogens, vol. 10, no. 12, Article ID e1004528, 2014.

[35] S. Pai, J. Qin, L. Cavanagh et al., "Real-time imaging reveals the dynamics of leukocyte behaviour during experimental cerebral malaria pathogenesis," PLoS Pathogens, vol. 10, no. 7, Article ID e1004236, 2014.

[36] A. Nacer, A. Movila, K. Baer, S. A. Mikolajczak, S. H. I. Kappe, and U. Frevert, "Neuroimmunological blood brain barrier opening in experimental cerebral malaria," PLoS Pathogens, vol. 8, no. 10, Article ID e1002982, 2012.

[37] U. Frevert, A. Nacer, M. Cabrera, A. Movila, and M. Leberl, "Imaging Plasmodium immunobiology in the liver, brain, and lung," Parasitology International, vol. 63, no. 1, pp. 171-186, 2014.

[38] G. Senaldi, C. Vesin, R. Chang, G. E. Grau, and P. F. Piguet, "Role of polymorphonuclear neutrophil leukocytes and their integrin CD1la (LFA-1) in the pathogenesis of severe murine malaria," Infection and Immunity, vol. 62, no. 4, pp. 1144-1149, 1994.

[39] T. N. Ramos, D. C. Bullard, M. M. Darley, K. McDonald, D. F. Crawford, and S. R. Barnum, "Experimental cerebral malaria develops independently of endothelial expression of intercellular adhesion molecule-1 (ICAM-1)," The Journal of Biological Chemistry, vol. 288, no. 16, pp. 10962-10966, 2013.

[40] R. Jambou, V. Combes, M.-J. Jambou, B. B. Weksler, P.-O. Couraud, and G. E. Grau, "Plasmodium falciparum adhesion on human brain microvascular endothelial cells involves transmigration-like cup formation and induces opening of intercellular junctions," PLoS Pathogens, vol. 6, no. 7, Article ID e1001021, 2010.

[41] S. W. Howland, C. M. Poh, L. Rénia, and J. Langhorne, "Activated brain endothelial cells cross-present malaria antigen," PLOS Pathogens, vol. 11, no. 6, Article ID e1004963, 2015.

[42] T. Owens, I. Bechmann, and B. Engelhardt, "Perivascular spaces and the two steps to neuroinflammation," Journal of Neuropathology \& Experimental Neurology, vol. 67, no. 12, pp. 1113-1121, 2008.

[43] A. Louveau, I. Smirnov, T. J. Keyes et al., "Structural and functional features of central nervous system lymphatic vessels," Nature, vol. 523, no. 7560, pp. 337-341, 2015.

[44] A. J. Sweatt and J. E. Levitt, "Evolving epidemiology and definitions of the acute respiratory distress syndrome and early acute lung injury," Clinics in Chest Medicine, vol. 35, no. 4, pp. 609-624, 2014.

[45] M. C. Souza, J. D. Silva, T. A. Pádua, V. L. Capelozzi, P. R. M. Rocco, and M. D. G. Henriques, "Early and late acute lung injury and their association with distal organ damage in murine malaria," Respiratory Physiology \& Neurobiology, vol. 186, no. 1, pp. 65-72, 2013.

[46] E. H. Aitken, E. M. Negri, R. Barboza et al., "Ultrastructure of the lung in a murine model of malaria-associated acute lung injury/acute respiratory distress syndrome," Malaria Journal, vol. 13, article 230, 2014.

[47] S. Epiphanio, M. G. Campos, A. Pamplona et al., "VEGF promotes malaria-associated acute lung injury in mice," PLoS Pathogens, vol. 6, no. 5, Article ID e1000916, 2010.

[48] L. S. Ortolan, M. K. Sercundes, R. Barboza et al., "Predictive criteria to study the pathogenesis of malaria-associated ALI/ARDS in mice," Mediators of Inflammation, vol. 2014, Article ID 872464, 12 pages, 2014.

[49] F. E. Lovegrove, L. Peña-Castillo, N. Mohammad, W. C. Liles, T. R. Hughes, and K. C. Kain, "Simultaneous host and parasite expression profiling identifies tissue-specific transcriptional programs associated with susceptibility or resistance to experimental cerebral malaria," BMC Genomics, vol. 7, article 295, 2006.

[50] K. Baer, C. Klotz, S. H. I. Kappe, T. Schnieder, and U. Frevert, "Release of hepatic Plasmodium yoelii merozoites into the pulmonary microvasculature," PLoS Pathogens, vol. 3, article e171, 2007.

[51] S. Thiberge, S. Blazquez, P. Baldacci et al., "In vivo imaging of malaria parasites in the murine liver," Nature Protocols, vol. 2, no. 7, pp. 1811-1818, 2007.

[52] K. Deroost, A. Tyberghein, N. Lays et al., "Hemozoin induces lung inflammation and correlates with malaria-associated acute respiratory distress syndrome," American Journal of Respiratory Cell and Molecular Biology, vol. 48, no. 5, pp. 589-600, 2013.

[53] P. E. Van den Steen, N. Geurts, K. Deroost et al., "Immunopathology and dexamethasone therapy in a new model for malaria-associated acute respiratory distress syndrome," American Journal of Respiratory and Critical Care Medicine, vol. 181, no. 9, pp. 957-968, 2010.

[54] E. Belnoue, S. M. Potter, D. S. Rosa et al., "Control of pathogenic $\mathrm{CD}^{+} \mathrm{T}$ cell migration to the brain by IFN-gamma during experimental cerebral malaria," Parasite Immunology, vol. 30, no. 10 , pp. 544-553, 2008.

[55] M. R. Looney, E. E. Thornton, D. Sen, W. J. Lamm, R. W. Glenny, and M. F. Krummel, "Stabilized imaging of immune surveillance in the mouse lung," Nature Methods, vol. 8, no. 1, pp. 91-96, 2011.

[56] V. R. Krishnamurthy, M. Y. Sardar, Y. Ying et al., "Glycopeptide analogues of PSGL-1 inhibit P-selectin in vitro and in vivo," Nature Communications, vol. 6, article 6387, 2015.

[57] C. R. Parish, "The role of heparan sulphate in inflammation," Nature Reviews Immunology, vol. 6, no. 9, pp. 633-643, 2006.

[58] V. Combes, A. R. Rosenkranz, M. Redard et al., "athogenic role of P-selectin in experimental cerebral malaria: importance of the endothelial compartment," American Journal of Pathology, vol. 164, no. 3, pp. 781-786, 2004.

[59] N. Favre, C. da Laperousaz, B. Ryffel et al., "Role of ICAM1 (CD54) in the development of murine cerebral malaria," Microbes and Infection, vol. 1, no. 12, pp. 961-968, 1999.

[60] J. Li, W.-L. Chang, G. Sun et al., "Intercellular adhesion molecule 1 is important for the development of severe experimental malaria but is not required for leukocyte adhesion in the brain," The Journal of Investigative Medicine, vol. 51, no. 3, pp. 128-140, 2003.

[61] W. C. Aird, "Phenotypic heterogeneity of the endothelium: I. Structure, function, and mechanisms," Circulation Research, vol. 100, no. 2, pp. 158-173, 2007.

[62] L. E. Craig, J. P. Spelman, J. D. Strandberg, and M. C. Zink, "Endothelial cells from diverse tissues exhibit differences in growth and morphology," Microvascular Research, vol. 55, no. 1, pp. 65-76, 1998.

[63] M. R. Gillrie, G. Krishnegowda, K. Lee et al., "Src-family kinase-dependent disruption of endothelial barrier function by Plasmodium falciparum merozoite proteins," Blood, vol. 110, no. 9, pp. 3426-3435, 2007.

[64] P. Fu, P. V. Usatyuk, A. Lele et al., "c-Abl mediated tyrosine phosphorylation of paxillin regulates LPS-induced endothelial dysfunction and lung injury," American Journal of PhysiologyLung Cellular and Molecular Physiology, vol. 308, no. 10, pp. L1025-L1038, 2015. 
[65] F. Wessel, M. Winderlich, M. Holm et al., "Leukocyte extravasation and vascular permeability are each controlled in vivo by different tyrosine residues of VE-cadherin," Nature Immunology, vol. 15, no. 3, pp. 223-230, 2014.

[66] P. F. Piguet, C. Da Laperrousaz, C. Vesin, F. Tacchini-Cottier, G. Senaldi, and G. E. Grau, "Delayed mortality and attenuated thrombocytopenia associated with severe malaria in urokinaseand urokinase receptor-deficient mice," Infection and Immunity, vol. 68 , no. 7, pp. 3822-3829, 2000.

[67] R. T. Amison, S. Momi, A. Morris et al., "RhoA signaling through platelet $\mathrm{P} 2 \mathrm{Y}(1)$ receptor controls leukocyte recruitment in allergic mice," Journal of Allergy and Clinical Immunology, vol. 135, no. 2, pp. 528-538, 2014.

[68] R. F. Xie, P. Hu, Z. C. Wang et al., "Platelet-derived microparticles induce polymorphonuclear leukocyte-mediated damage of human pulmonary microvascular endothelial cells," Transfusion, vol. 55, no. 5, pp. 1051-1057, 2015.

[69] C. Alves, J.-T. Chen, N. Patel et al., "Extracorporeal membrane oxygenation for refractory acute respiratory distress syndrome in severe malaria," Malaria Journal, vol. 12, article 306, 2013.

[70] T. W. Yeo, D. A. Lampah, R. Gitawati et al., "Impaired nitric oxide bioavailability and L-arginine-reversible endothelial dysfunction in adults with Falciparum malaria," The Journal of Experimental Medicine, vol. 204, no. 11, pp. 2693-2704, 2007.

[71] T. P. Abreu, L. S. Silva, C. M. Takiya et al., "Mice rescued from severe malaria are protected against renal injury during a second kidney insult," PLOS ONE, vol. 9, no. 4, Article ID e93634, 2014.

[72] A. E. P. Frosch and C. C. John, "Immunomodulation in Plasmodium falciparum malaria: experiments in nature and their conflicting implications for potential therapeutic agents," Expert Review of Anti-Infective Therapy, vol. 10, no. 11, pp. 13431356, 2012.

[73] G. Watt, K. Jongsakul, and R. Ruangvirayuth, "A pilot study of $\mathrm{N}$-acetylcysteine as adjunctive therapy for severe malaria," QJM, vol. 95, no. 5, pp. 285-290, 2002.

[74] A. K. Boggild, S. Krudsood, S. N. Patel et al., "Use of peroxisome proliferator-activated receptor $\gamma$ agonists as adjunctive treatment for Plasmodium falciparum malaria: a randomized, double-blind, placebo-controlled trial," Clinical Infectious Diseases, vol. 49, no. 6, pp. 841-849, 2009.

[75] L. Serghides, C. R. McDonald, Z. Lu et al., "PPAR $\gamma$ agonists improve survival and neurocognitive outcomes in experimental cerebral malaria and induce neuroprotective pathways in human malaria," PLoS Pathogens, vol. 10, no. 3, Article ID e1003980, 2014.

[76] T. W. Yeo, D. A. Lampah, I. Rooslamiati et al., "A randomized pilot study of L-arginine infusion in severe Falciparum malaria: preliminary safety, efficacy and pharmacokinetics," PLoS ONE, vol. 8, no. 7, Article ID e69587, 2013.

[77] A. M. Dondorp, K. Silamut, P. Charunwatthana et al., "Levamisole inhibits sequestration of infected red blood cells in patients with falciparum malaria," Journal of Infectious Diseases, vol. 196, no. 3, pp. 460-466, 2007.

[78] A. Dondorp, F. Nosten, K. Stepniewska, N. Day, and N. White, "Artesunate versus quinine for treatment of severe falciparum malaria: a randomised trial," The Lancet, vol. 366, no. 9487, pp. 717-725, 2005.

[79] M. E. Sarciron, C. Saccharin, A. F. Petavy, and F. Peyron, "Effects of artesunate, dihydroartemisinin, and an artesunatedihydroartemisinin combination against Toxoplasma gondii,"
The American Journal of Tropical Medicine and Hygiene, vol. 62, no. 1, pp. 73-76, 2000.

[80] T. Efferth, H. Dunstan, A. Sauerbrey, H. Miyachi, and C. R. Chitambar, "The anti-malarial artesunate is also active against cancer," International Journal of Oncology, vol. 18, no. 4, pp. 767773, 2001.

[81] S. J. F. Kaptein, T. Efferth, M. Leis et al., "The anti-malaria drug artesunate inhibits replication of cytomegalovirus in vitro and in vivo," Antiviral Research, vol. 69, no. 2, pp. 60-69, 2006.

[82] J. Wang, H. Zhou, J. Zheng et al., “The antimalarial artemisinin synergizes with antibiotics to protect against lethal live Eschenchia coli challenge by decreasing proinflammatory cytokine release," Antimicrobial Agents and Chemotherapy, vol. 50, no. 7, pp. 2420-2427, 2006.

[83] M. C. Souza, F. H. Paixao, F. K. Ferraris, I. Ribeiro, and M. Henriques, "Artesunate exerts a direct effect on endothelial cell activation and NF-kappaB translocation in a mechanism independent of plasmodium killing," Malaria Research and Treatment, vol. 2012, Article ID 679090, 12 pages, 2012.

[84] R. Srinivas, R. Agarwal, and D. Gupta, "Severe sepsis due to severe falciparum malaria and leptospirosis co-infection treated with activated protein C," Malaria Journal, vol. 6, article 42, 2007.

[85] C. Guitton, A. Cottereau, N. Gérard et al., "Protective cross talk between activated protein $\mathrm{C}$ and TNF signaling in vascular endothelial cells: implication of EPCR, noncanonical NF- $\kappa \mathrm{B}$, and ERK1/2 MAP kinases," American Journal of PhysiologyCell Physiology, vol. 300, no. 4, pp. C833-C842, 2011.

[86] M. Riewald and R. A. Schuepbach, "Protective signaling pathways of activated protein C in endothelial cells," Arteriosclerosis, Thrombosis, and Vascular Biology, vol. 28, no. 1, pp. 1-3, 2008.

[87] J. Dormoi, S. Briolant, A. Pascual, C. Desgrouas, C. Travaillé, and B. Pradines, "Improvement of the efficacy of dihydroartemisinin with atorvastatin in an experimental cerebral malaria murine model," Malaria Journal, vol. 12, article 302, 2013.

[88] P. A. Reis, V. Estato, T. I. da Silva et al., "Statins decrease neuroinflammation and prevent cognitive impairment after cerebral malaria," PLoS Pathogens, vol. 8, no. 12, Article ID e1003099, 2012.

[89] G. Weitz-Schmidt, K. Welzenbach, V. Brinkmann et al., "Statins selectively inhibit leukocyte function antigen-1 by binding to a novel regulatory integrin site," Nature Medicine, vol. 7, no. 6, pp. 687-692, 2001.

[90] Z. Taoufiq, P. Pino, N. N’Dilimabaka et al., "Atorvastatin prevents Plasmodium falciparum cytoadherence and endothelial damage," Malaria Journal, vol. 10, article 52, 2011.

[91] S.-Y. Ou, H. Chu, P.-W. Chao et al., "Effect of the use of low and high potency statins and sepsis outcomes," Intensive Care Medicine, vol. 40, no. 10, pp. 1509-1517, 2014.

[92] C. A. Finney, C. A. Hawkes, D. C. Kain et al., "S1P is associated with protection in human and experimental cerebral malaria," Molecular Medicine, vol. 17, no. 7-8, pp. 717-725, 2011.

[93] M. C. Souza, J. D. Silva, T. A. Padua et al., "Mesenchymal stromal cell therapy attenuated lung and kidney injury but not brain damage in experimental cerebral malaria," Stem Cell Research \& Therapy, vol. 6, pp. 102-117, 2015.

[94] A. Nacer, A. Claes, A. Roberts et al., "Discovery of a novel and conserved Plasmodium falciparum exported protein that is important for adhesion of PfEMP1 at the surface of infected erythrocytes," Cellular Microbiology, vol. 17, no. 8, pp. 1205-1216, 2015. 
[95] W. Solomon, N. O. Wilson, L. Anderson et al., "Neuregulin1 attenuates mortality associated with experimental cerebral malaria," Journal of Neuroinflammation, vol. 11, article 9, 2014.

[96] R. Schweizer, P. Kamat, D. Schweizer et al., "Bone marrowderived mesenchymal stromal cells improve vascular regeneration and reduce leukocyte-endothelium activation in critical ischemic murine skin in a dose-dependent manner," Cytotherapy, vol. 16, no. 10, pp. 1345-1360, 2014.

[97] T. Maron-Gutierrez, J. G. Laffey, P. Pelosi, and P. R. M. Rocco, "Cell-based therapies for the acute respiratory distress syndrome," Current Opinion in Critical Care, vol. 20, no. 1, pp. 122-131, 2014.

[98] A. Ryan and C. Godson, "Lipoxins: regulators of resolution," Current Opinion in Pharmacology, vol. 10, no. 2, pp. 166-172, 2010.

[99] O. Haworth, M. Cernadas, R. Yang, C. N. Serhan, and B. D. Levy, "Resolvin E1 regulates interleukin 23, interferon- $\gamma$ and lipoxin A4 to promote the resolution of allergic airway inflammation," Nature Immunology, vol. 9, no. 8, pp. 873-879, 2008.

[100] M. M.-Y. Chan and A. R. Moore, "Resolution of inflammation in murine autoimmune arthritis is disrupted by cyclooxygenase- 2 inhibition and restored by prostaglandin $\mathrm{E}_{2}$-mediated lipoxin $\mathrm{A}_{4}$ production," The Journal of Immunology, vol. 184, no. 11, pp. 6418-6426, 2010.

[101] S. Fiorucci, E. Distrutti, A. Mencarelli et al., "Evidence that 5lipoxygenase and acetylated cyclooxygenase 2-derived eicosanoids regulate leukocyte-endothelial adherence in response to aspirin," British Journal of Pharmacology, vol. 139, no. 7, pp. 13511359, 2003.

[102] N. Shryock, C. McBerry, R. M. S. Gonzalez, S. Janes, F. T. M. Costa, and J. Aliberti, "Lipoxin $\mathrm{A}_{4}$ and 15-epi-lipoxin $\mathrm{A}_{4}$ protect against experimental cerebral malaria by inhibiting IL-12/IFN- $\gamma$ in the brain," PLoS ONE, vol. 8, no. 4, Article ID e61882, 2013.

[103] Y.-F. Wang, Y.-T. Gu, G.-H. Qin, L. Zhong, and Y.-N. Meng, "Curcumin ameliorates the permeability of the blood-brain barrier during hypoxia by upregulating heme oxygenase-1 expression in brain microvascular endothelial cells," Journal of Molecular Neuroscience, vol. 51, no. 2, pp. 344-351, 2013.

[104] C.-Y. Lu, Y.-C. Yang, C.-C. Li, K.-L. Liu, C.-K. Lii, and H.-W. Chen, "Andrographolide inhibits TNF $\alpha$-induced ICAM1 expression via suppression of NADPH oxidase activation and induction of HO-1 and GCLM expression through the PI3K/Akt/Nrf2 and PI3K/Akt/AP-1 pathways in human endothelial cells," Biochemical Pharmacology, vol. 91, no. 1, pp. 40-50, 2014.

[105] A. Belhaj, L. Dewachter, F. Kerbaul et al., "Heme oxygenase-1 and inflammation in experimental right ventricular failure on prolonged overcirculation-induced pulmonary hypertension," PLoS ONE, vol. 8, no. 7, Article ID e69470, 2013.

[106] A. Pamplona, A. Ferreira, J. Balla et al., "Heme oxygenase-1 and carbon monoxide suppress the pathogenesis of experimental cerebral malaria," Nature Medicine, vol. 13, no. 6, pp. 703-710, 2007.

[107] E. Seixas, R. Gozzelino, Â. Chora et al., "Heme oxygenase-1 affords protection against noncerebral forms of severe malaria," Proceedings of the National Academy of Sciences of the United States of America, vol. 106, no. 37, pp. 15837-15842, 2009.

[108] L. J. de Moura Carvalho, A. da Silva Moreira, C. T. DanielRibeiro, and Y. C. Martins, "Vascular dysfunction as a target for adjuvant therapy in cerebral malaria," Memorias do Instituto Oswaldo Cruz, vol. 109, no. 5, pp. 577-588, 2014.
[109] T. W. Yeo, D. A. Lampah, E. Kenangalem et al., "Decreased endothelial nitric oxide bioavailability, impaired microvascular function, and increased tissue oxygen consumption in children with falciparum malaria," The Journal of Infectious Diseases, vol. 210, no. 10, pp. 1627-1632, 2014.

[110] M. Hawkes, R. O. Opoka, S. Namasopo et al., "Inhaled nitric oxide for the adjunctive therapy of severe malaria: protocol for a randomized controlled trial," Trials, vol. 12, article 176, 2011.

[111] B. Bergmark, R. Bergmark, P. D. Beaudrap et al., "Inhaled nitric oxide and cerebral malaria: basis of a strategy for buying time for pharmacotherapy," Pediatric Infectious Disease Journal, vol. 31, no. 12, pp. e250-e254, 2012.

[112] C. Bogdan, "Nitric oxide synthase in innate and adaptive immunity: an update," Trends in Immunology, vol. 36, no. 3, pp. 161-178, 2015.

[113] P. Cabrales, G. M. Zanini, D. Meays, J. A. Frangos, and L. J. M. Carvalho, "Nitric oxide protection against murine cerebral malaria is associated with improved cerebral microcirculatory physiology," Journal of Infectious Diseases, vol. 203, no. 10, pp. 1454-1463, 2011.

[114] G. M. Zanini, P. Cabrales, W. Barkho, J. A. Frangos, and L. J. M. Carvalho, "Exogenous nitric oxide decreases brain vascular inflammation, leakage and venular resistance during Plasmodium berghei ANKA infection in mice," Journal of Neuroinflammation, vol. 8, article 66, 2011.

[115] J. Lou, R. Lucas, and G. E. Grau, "Pathogenesis of cerebral malaria: recent experimental data and possible applications for humans," Clinical Microbiology Reviews, vol. 14, no. 4, pp. 810820, 2001.

[116] J. B. de Souza, J. C. R. Hafalla, E. M. Riley, and K. N. Couper, "Cerebral malaria: why experimental murine models are required to understand the pathogenesis of disease," Parasitology, vol. 137, no. 5, pp. 755-772, 2010.

[117] A. G. Craig, G. E. Grau, C. Janse et al., "The role of animal models for research on severe malaria," PLoS Pathogens, vol. 8, no. 2, Article ID e1002401, 2012.

[118] L. J. M. Carvalho, "Murine cerebral malaria: how far from human cerebral malaria?" Trends in Parasitology, vol. 26, no. 6, pp. 271-272, 2010. 


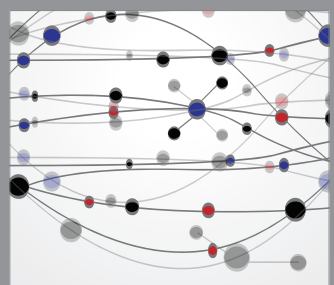

The Scientific World Journal
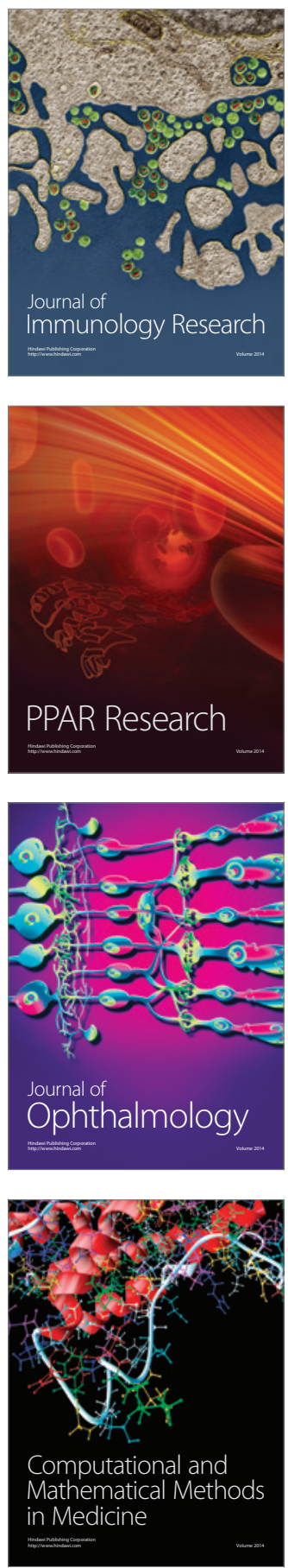

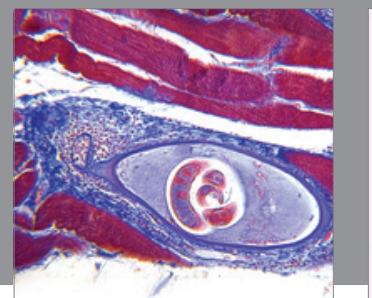

Gastroenterology

Research and Practice
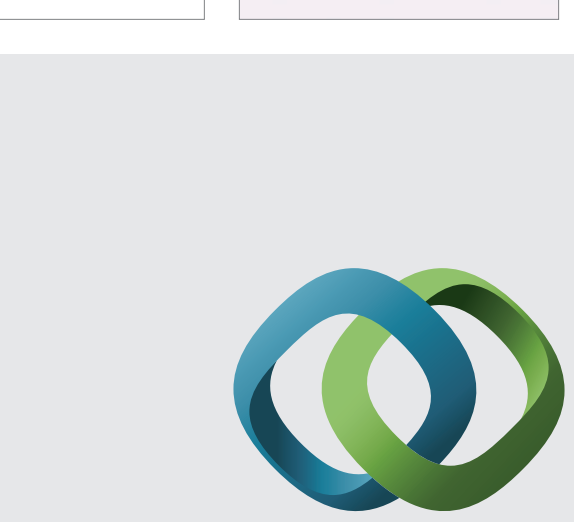

\section{Hindawi}

Submit your manuscripts at

http://www.hindawi.com
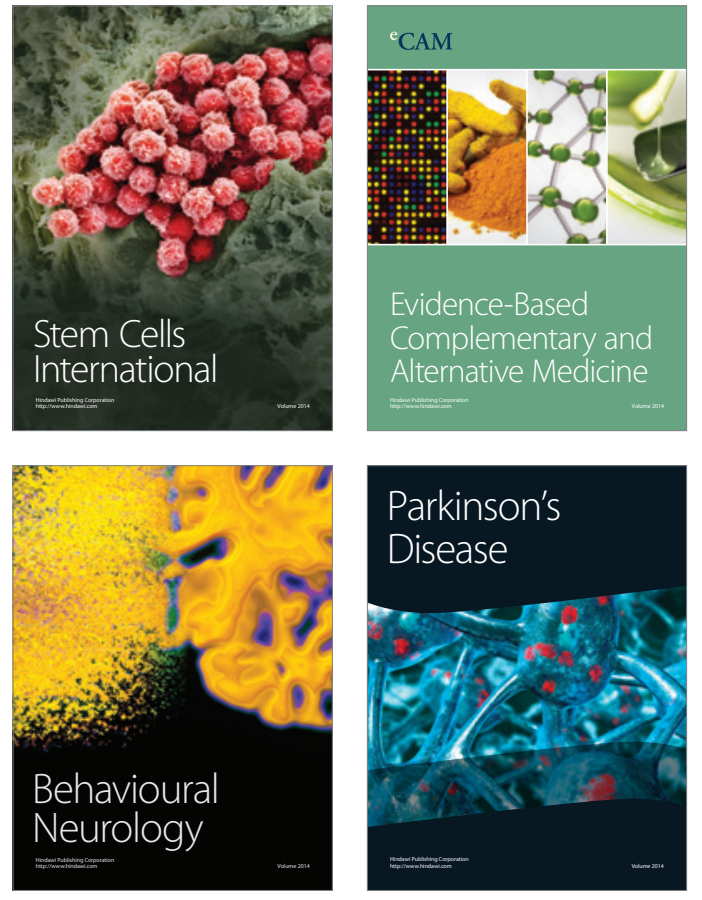
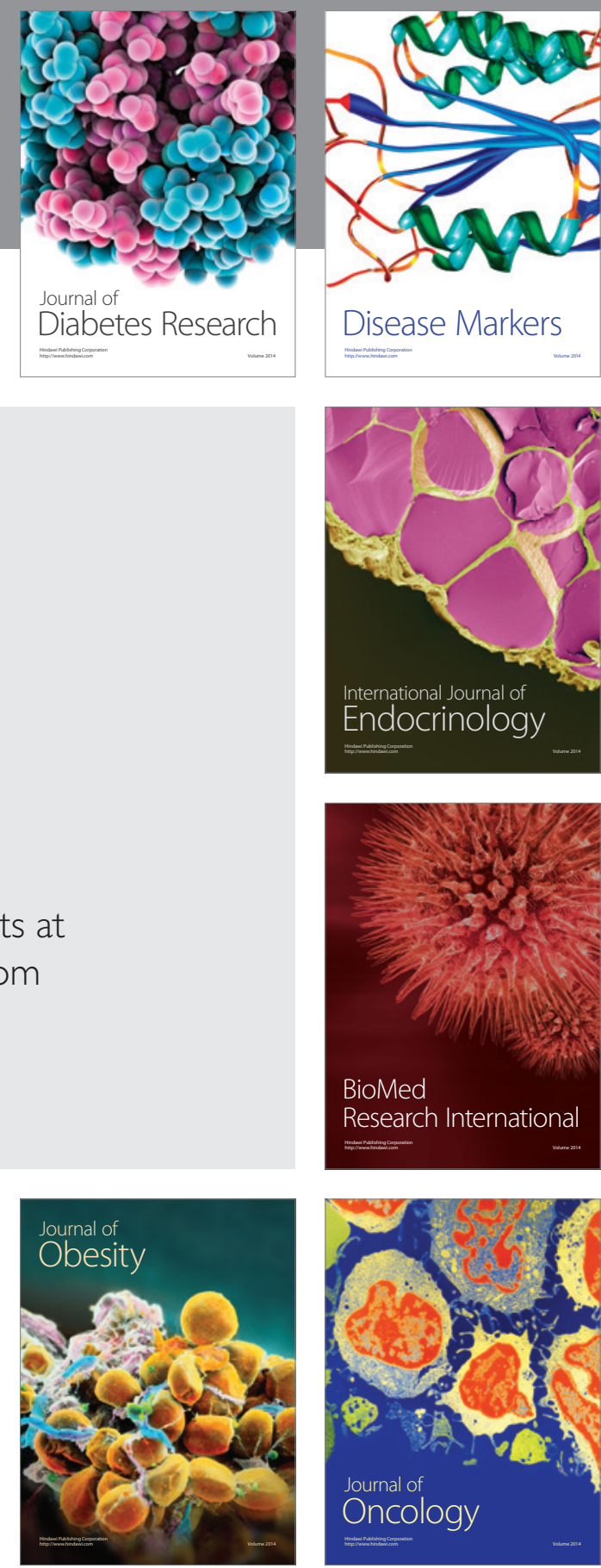

Disease Markers
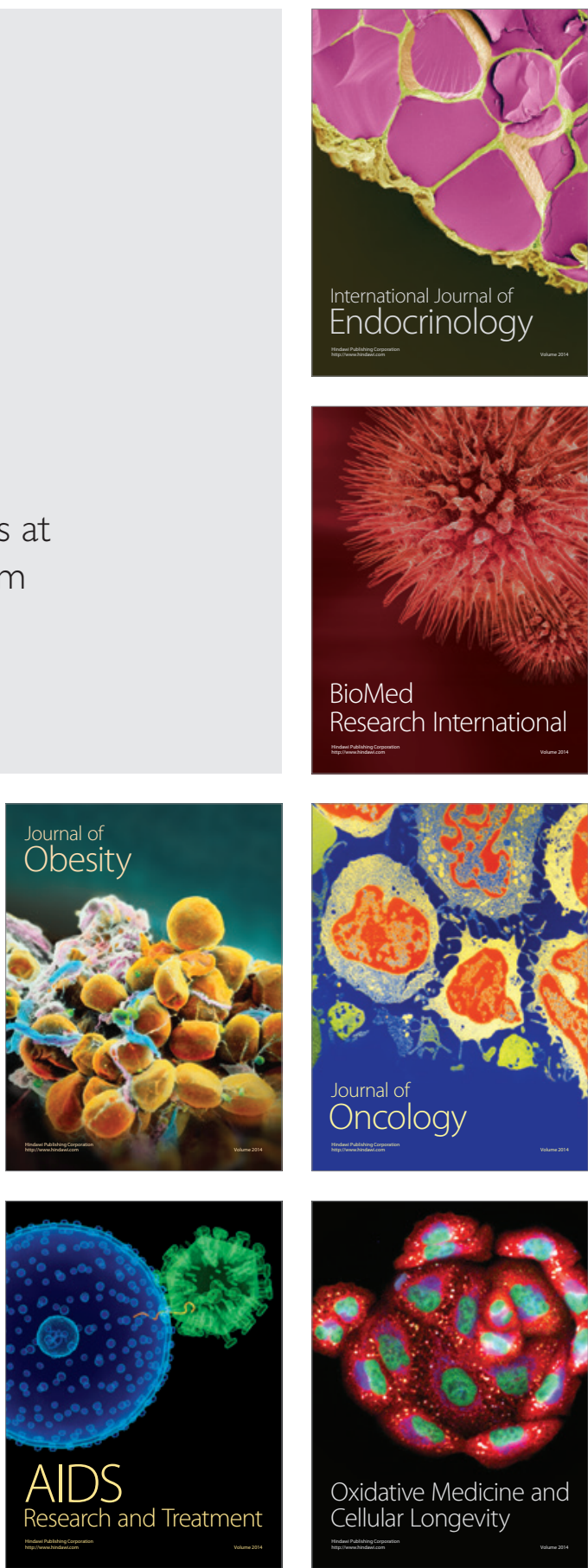